\title{
Occurrence of plasmids in pathogenic strains of Nocardia
}

\author{
FREDERIQUE PROVOST, MARIE V. BLANC, B. L. BEAMAN* and P. BOIRON \\ Institut Pasteur, Unit of Mycology, 28 rue du Docteur Roux, 75724 Paris Cedex 15, France and *Department of \\ Medical Microbiology, School of Medicine, University of California, Davis, CA 95616, USA
}

\begin{abstract}
The purpose of the present study was to determine the relative distribution of plasmids in 87 clinical isolates of Nocardia, belonging to the five major pathogenic species. A correlation between plasmid content and the site of infection within the host, resistance to antibiotics and enzymic profiles was also investigated. The plasmid extraction procedure of Kado and Liu was used. Electrophoretic analysis revealed one-to-four plasmid bands, ranging in size from $<8$ to $>50 \mathrm{~kb}$, in 27 strains $(31 \%)$. Based on the number of isolates tested, the incidence of plasmid-bearing strains was significantly higher among $N$. farcinica than $N$. asteroides strains. Within $N$. farcinica, the incidence of plasmids was higher among strains isolated in the Paris area than in strains isolated elsewhere, such as in the French provinces or outside France. A statistically significant correlation was demonstrated between the cutaneous localisation of infections and the incidence of plasmid-bearing strains. The presence of plasmids in nocardiae could not be associated with specific phenotypic traits such as resistance to antibiotics or enzymic activity. The fact that the majority of Nocardia clinical isolates (60 of 87) did not contain plasmids suggests that plasmids are not involved directly in virulence and that there is no selective pressure for plasmid acquisition.
\end{abstract}

\section{Introduction}

Nocardia spp. are gram-positive aerobic actinomycetes with rudimentary to extensively branched vegetative hyphae that fragment into bacteroid, rod-shaped to coccoid elements. The DNA of these organisms have a $\mathrm{G}+\mathrm{C}$ content ranging from 64 to $72 \mathrm{~mol} \%$ and their cell walls contain mycolic acids composed of 46-60 carbon atoms. Nocardiae have a worldwide distribution in soil and some strains are pathogenic for man and animals [1]. They may enter the body via inhalation of contaminated dust particles or wounds contaminated with dust or soil. In recent years, pulmonary and systemic human infections have been reported most frequently in immunocompromised patients [2].

Evidence for plasmid carriage may be of special interest because plasmids could encode for important phenotypic properties as well as specific virulence factors. There are very few reports of plasmid carriage within true Nocardia spp., and these have referred mainly to $N$. asteroides isolates [3,4]. However, it is known that strains previously identified simply as $N$. asteroides are in fact members of the $N$. asteroides

Received 15 Jan. 1996; accepted 15 March 1996. Corresponding author: Dr P. Boiron. general complex, and this group must be differentiated now into at least three species, i.e., $N$. asteroides sensu stricto (here called $N$. asteroides), $N$. farcinica and $N$. nova. Their epidemiological [5], pathogenic [6] and antibiotic susceptibility patterns seem to be different $[7,8]$, which might lead to distinct clinical outcomes in infected patients [5].

The purposes of the present study were: (a) to screen a large number of clinical isolates of Nocardia, including strains belonging to the $N$. asteroides complex, to determine the relative distribution of plasmids; (b) to examine the correlation between plasmid content and phenotypes, resistance to antibiotics and enzymic profiles; (c) to investigate the relationships between plasmid content of clinical isolates and the site of infection within the host; and (d) to evaluate the stability of plasmid carriage.

\section{Materials and methods}

\section{Bacterial strains and media}

Eighty-seven strains of nocardiae isolated from human infections were used in this study. They included 79 strains of the $N$. asteroides complex (46 N. asteroides, $23 N$. farcinica, $10 \mathrm{~N}$. nova), four $N$. brasiliensis and 
four $N$. otitidiscaviarum; they were isolated from patients with nocardiosis and cultured from specimens submitted to the National Reference Center for Human Mycosis and Antifungal Agents (Institut Pasteur, Paris, France) over a 5-year period (1990-1994). The strains were isolated from various sites of infection: lung (LU, 36 isolates), brain (BR, nine isolates), primary cutaneous (CU, 11 isolates), other single localisation (SL, six isolates) and multiple localisations (ML, eight isolates). These isolates came predominantly from France (60 strains, including 16 strains isolated in the Paris area and 44 strains isolated in French provinces). Other strains were from Italy (six strains), Switzerland and Martinique (two strains from each country), and Algeria and Portugal (one strain from each country). In addition, 10 isolates from human nocardiosis were received from the University of California, Davis, CA, USA. Type strains of each species obtained from the American Type Culture Collection (ATCC, Rockville, MD, USA) were also included in this study (i.e., $N$. asteroides ATCC 19247, N. farcinica ATCC 3318, N. nova ATCC 33726, N. brasiliensis ATCC 19296 and $N$. otitidiscaviarum ATCC 14629). Isolates were maintained at $4^{\circ} \mathrm{C}$ on Bennett's agar slants [9].

\section{Culture conditions and identification}

Each strain was identified by standard tests including colony and microscopic morphology, staining characteristics, cell-wall type [10], mycolic acid composition [11] and physiological properties [1].

\section{Plasmid screening}

The plasmid extraction procedure of Kado and Liu [12] was used. Briefly, covalently closed circular DNA was released from cells under conditions that denature chromosomal DNA by alkaline sodium dodecyl sulphate $\left(\mathrm{pH} \mathrm{12.6)}\right.$ extraction at $65^{\circ} \mathrm{C}$. Proteins and cell debris were removed by extraction with phenol-chloroform and the clarified plasmid DNA extract was used directly for electrophoretic analysis. The strain of Klebsiella serotype 35 Dd, harbouring the plasmid pIP55 with a mol.wt of c. $130 \mathrm{~kb}$, was used as a control for the extraction of a high mol.wt plasmid [13]. Plasmid DNA extracts $(20 \mu \mathrm{l})$ were loaded into horizontal Seakem ME (FMC BioProducts, Rockland, ME, USA) agarose $0.5 \%$ gels $(15 \times 15 \mathrm{~cm})$. The samples were electrophoresed at $25 \mathrm{~V}$ constant voltage in $1 \times$ Tris-acetate EDTA buffer as described by Sambrook et al. [14], until the bromophenol blue tracking dye traversed the gel $(c .16 \mathrm{~h})$. Subsequently, the gel was stained with ethidium bromide $1 \mu \mathrm{g} / \mathrm{ml}$. Plasmid DNA bands were viewed with an ultraviolet transilluminator and photographed (Fotodyne Inc., New Berlin, WI, USA) with landscape polaroid negative film (no. 667). The approximate $\mathrm{M}_{\mathrm{r}}$ of plasmids, in $\mathrm{kb}$, was determined by comparing with a supercoiled DNA ladder and high mol.wt DNA markers (Gibco BRL, Gaithersburg, MD, USA).

\section{Antibiotic susceptibility}

In-vitro susceptibility testing was performed on Mueller-Hinton agar by a procedure described previously [15]. Briefly, a homogeneous suspension of organisms was prepared by shaking cultures in Mueller-Hinton broth containing sterile glass beads to decrease aggregation of the nocardial cells and incubating for $24-48 \mathrm{~h}$ at $35^{\circ} \mathrm{C}$. An inoculum yielding c. $10^{4}-10^{5} \mathrm{cfu} /$ $\mathrm{ml}$ was used for disk susceptibility testing, which was performed on Mueller-Hinton agar and read after incubation for $24-48 \mathrm{~h}$ at $37^{\circ} \mathrm{C}$. The antibiotics tested (Sanofi Diagnostics Pasteur, Marnes-la-Coquette, France) were ampicillin (Am), amoxycillin (Amx), cefamandole (Ma), imipenem (Ipm), cefuroxime $(\mathrm{Cxm})$, cefoxitine (Fox), cefotaxime (Ctx), ceftriaxone (Cro), tetracycline (Te), minocycline (Mno), doxycycline (Do), kanamycin (K), tobramycin (Tm), amikacin $(\mathrm{An})$, gentamicin $(\mathrm{Gm})$, chloramphenicol $(\mathrm{C})$, erythromycin (E) and clindamycin $(\mathrm{Cm})$. All strains were tested at least twice without any discrepancy between the results. The strains were scored as susceptible, intermediate or resistant according to the guidelines of the Antibiogram Committee of the French Society for Microbiology [16].

\section{Enzymic characterisation}

Enzymic profiles of strains were determined by the API ZYM system (API System SA, La Balme les Grottes, France) as previously described [17]. All tests were done with standardised inoculum size, temperature and duration of incubation as described previously.

\section{Plasmid stability}

The plasmid-containing strains were subcultured at intervals of 2 weeks and plasmid DNA preparations were repeated three times at intervals of 2 months. This corresponded to four subcultures between the first and the last DNA extractions.

\section{Statistical analysis}

The incidences of plasmids in Nocardia spp. were compared by the $\chi^{2}$ test.

\section{Results}

\section{Occurrence of plasmid-bearing strains}

Eighty-seven strains of Nocardia spp. isolated from clinical cases were examined. In 27 strains (31\%), electrophoretic analysis with agarose $0.5 \%$ gel revealed one-to-four plasmids, ranging in size from $<8$ to $>50 \mathrm{~kb}$ (Table 1). Plasmids with mobility faster than chromosomal residues $(c .40 \mathrm{~kb})$ were considered low mol.wt plasmids, whereas plasmids with mobility slower than chromosomal residues were considered high mol.wt plasmids. Plasmid DNA, either of low or high mol.wt, was demonstrated in all Nocardia spp. 
Table 1. Geographic origin, source, plasmid band profile and resistance-pattern of Nocardia spp.

\begin{tabular}{|c|c|c|c|c|}
\hline $\begin{array}{l}\text { Species and } \\
\text { strain number }\end{array}$ & Place & Source & $\begin{array}{l}\text { Plasmid profile } \\
(\mathrm{kb})\end{array}$ & Resistance pattern ${ }^{*}$ \\
\hline \multicolumn{5}{|l|}{ N. asteroides } \\
\hline $\mathrm{Nal}$ & Paris $^{\dagger}$ & LU & 15 & FoxC \\
\hline $\mathrm{Na} 2$ & Paris & $\mathrm{LU}$ & 29 & nd \\
\hline $\mathrm{Na3}$ & Nantes & LU & $10,12,17$ & TeCECm \\
\hline $\mathrm{Na} 4$ & Italy & BR & $10,12,24,38$ & FoxCroTeMnoDoKC \\
\hline $\mathrm{Na} 5$ & Algeria & LU & $38,>50$ & MaCxmFoxCtxTeMnoDoKCECm \\
\hline $\mathrm{Na} 6$ & USA & LU & $8,10,>50$ & AmAmxMaCxmFoxCtxCroTeDoKTmGmCECm \\
\hline $\mathrm{Na} 7$ & Bayonne & $\mathrm{LU}$ & $>50$ & $\mathrm{TeCCm}$ \\
\hline $\mathrm{Na} 8$ & Toulouse & $\mathrm{CU}$ & $>50$ & AmAmxTeKCECm \\
\hline $\mathrm{Na9}$ & Toulouse & $\mathrm{LU}$ & $>50$ & AmAmxMaFoxTeDoKTmGmCECm \\
\hline $\mathrm{Na} 10$ & Périgueux & ML & $>50$ & AmMaTeKCECm \\
\hline $\mathrm{Na} 11$ & Rodez & $\mathrm{LU}$ & $>50$ & AmMaIpmCm \\
\hline \multicolumn{5}{|l|}{ N. farcinica } \\
\hline $\mathrm{Nf1}$ & Paris & LU & 15 & AmMaCtxTeKTmGmCECm \\
\hline Nf2 & Paris & $\mathrm{CU}$ & 15,48 & AmAmxMaCxmFoxCtxCroTeMnoDoKTmGmCECm \\
\hline Nf3 & Paris & $\mathrm{CU}$ & $15,>50$ & AmAmxMaCxmFoxCtxCroTeMnoDoKTmGmCECm \\
\hline Nf4 & Besançon & LU & $15,>50$ & AmAmxMaCxmFoxCtxCroTeMnoDoKTmGmCECm \\
\hline Nf5 & Paris & LU & 50 & AmAmxMaCxmFoxCtxCroTeMnoDoKTmGmCECm \\
\hline Nf6 & Paris & LU & $>50$ & AmAmxMaCxmCtxCroTeMnoDoKTmGmCECm \\
\hline $\mathrm{Nf} 7$ & Paris & $\mathrm{CU}$ & $>50$ & AmAmxMaCxmFoxCtxCroTeMnoDoKTmGmCECm \\
\hline $\mathrm{Nf8}$ & Paris & $\mathrm{LU}$ & $>50$ & AmAmxMaCxmFoxCtxCroTeMnoDoKTmGmCECm \\
\hline $\mathrm{Nf9}$ & Tours & $\mathrm{CU}$ & $>50$ & AmAmxMaCxmFoxCtxCroTeMnoDoKTmGmCECm \\
\hline Nf10 & Lille & $\mathrm{CU}$ & $>50$ & AmAmxMaCxmFoxCtxCroTeMnoDoKTmGmCECm \\
\hline Nf11 & USA & LU & $>50$ & AmAmxMaCxmFoxCtxCroTeMnoDoKTmGmCECm \\
\hline \multicolumn{5}{|l|}{ N. nova } \\
\hline $\mathrm{Nn} 1$ & Amiens & ML & $<8$ & AmxFoxCroTeDoKTmGm \\
\hline $\mathrm{Nn} 2$ & Nantes & $\mathrm{CU}$ & $19,>50$ & AmMaCxmFoxCtxCroKTmGmCECm \\
\hline \multicolumn{5}{|c|}{ N. otitidiscaviarum } \\
\hline Nol & Toulouse & $\mathrm{CU}$ & 29,38 & AmAmxMaIpmCxmFoxCtxCroTeCE \\
\hline No2 & St Etienne & $\mathrm{CU}$ & $<8,8$ & AmFoxKAnGmCECmE \\
\hline \multicolumn{5}{|l|}{ N. brasiliensis } \\
\hline $\mathrm{Nb} 1$ & Portugal & $\mathrm{LU}$ & 17 & AmAmxMaIpmCxmFoxCtxK \\
\hline
\end{tabular}

* Strains were susceptible or intermediary to other antibiotics tested.

${ }^{\dagger}$ Paris area.

nd, not determined (because of severe clumping during growth).

studied, including $11(24 \%)$ of 46 strains of $N$. asteroides (sensu stricto), $11(48 \%)$ of 23 strains of $N$. farcinica, two of 10 strains of $N$. nova, one of four strains of $N$. brasiliensis and two of four strains of $N$. otitidiscaviarum. None of the type strains of the nocardial species contained plasmids. Based on the number of isolates tested, the incidence of plasmidbearing strains was significantly higher among $N$. farcinica than $N$. asteroides strains $(p<0.025)$. The number of strains of other nocardial species investigated was too low for frequency analysis of plasmidbearing strains.

Table 2 shows the geographic distribution of strains of $N$. asteroides and $N$. farcinica, either with or without

Table 2. Geographic distribution of strains of $N$. asteroides and $N$. farcinica

\begin{tabular}{lcc}
\hline & \multicolumn{2}{c}{ Number of strains from } \\
\cline { 2 - 3 } Species & Paris area & Other areas* \\
\hline$N$. asteroides & & \\
$\quad$ Plasmids & 2 & 9 \\
$\quad$ No plasmid & 4 & 31 \\
$N$. farcinica & & 4 \\
Plasmids & 7 & 10 \\
No plasmid & 2 & \\
\hline
\end{tabular}

*Including French provinces and other countries. plasmid bands. Within $N$. farcinica, the incidence of plasmids was higher among strains isolated in the Paris area than in strains isolated elsewhere, such as in the French provinces or outside France $(\mathrm{p}<0.1)$.

The site of infection was known for 71 strains (Table 3). A statistically significant correlation was demonstrated between the cutaneous localisation of infections and the incidence of plasmid-bearing strains $(\mathrm{p}<0.005)$. Thus, all $N$. asteroides and $N$. farcinica strains isolated from cutaneous infection contained a high mol. wt plasmid ( $\geqslant 50 \mathrm{~kb}$ ); however, $N$. otitidiscaviarum strains showed only low mol.wt plasmid bands $(<8,8,29$ and $38 \mathrm{~kb})$. In contrast, $N$. brasiliensis strains isolated from cutaneous lesions did not have any visible plasmid band.

Table 3. Site of infection of strains of Nocardia spp.

\begin{tabular}{lccccc}
\hline & \multicolumn{5}{c}{ Number of isolates from } \\
\cline { 2 - 6 } Species & $\mathrm{LU}$ & $\mathrm{BR}$ & $\mathrm{CU}$ & $\mathrm{SL}$ & $\mathrm{ML}$ \\
\hline N. asteroides & $23 / 8^{*}$ & $7 / 1$ & $1 / 1$ & $5 / 0$ & $3 / 1$ \\
N. farcinica & $9 / 6$ & $2 / 0$ & $5 / 5$ & - & $2 / 0$ \\
$N$. nova & $4 / 0$ & - & $1 / 1$ & $1 / 0$ & $2 / 1$ \\
N. brasiliensis & $1 / 1$ & - & $2 / 0$ & - & - \\
N. otitidiscaviarum & - & - & $2 / 2$ & - & $1 / 0$ \\
\hline
\end{tabular}

${ }^{*}$ Number of strains tested/number of plasmid-bearing strains. 


\section{Antibiotic susceptibility tests}

Table 1 shows the resistance profiles of plasmidcontaining strains against various antibiotics. The incidence of susceptibility amongst $N$. farcinica isolates was similar, showing resistance to all but two antibiotics (Ipm and An). In contrast, resistance was variable amongst $N$. asteroides isolates. The susceptibility of nocardial isolates to antibiotics did not correlate with the presence of plasmids.

\section{Enzymic characterisation}

Plasmid-bearing strains showed enzymic (physiological) profiles that were not significantly different from those isolates that had no demonstrable plasmids (data not shown).

\section{Plasmid stability}

For all strains, plasmid patterns were identical after at least 4 subcultures with those patterns identified during the first screening (data not shown).

\section{Discussion}

There have been only a few reports of plasmids in nocardiae. It should be noted that $N$. corallina, $N$. erythropolis, $N$. orientalis and $N$. mediterranei, from which plasmids have been isolated [18-21], are not members of the genus Nocardia but have been reassigned to the genus Rhodococcus for the two former species and Amycolatopsis for the two latter species. Up to the present, plasmids have been demonstrated only in a few isolates of $N$. asteroides $[3,4]$ which, based on taxonomic difficulties, might have been either $N$. asteroides sensu stricto, $N$. farcinica or $N$. nova.

Plasmid content and plasmid sizes may differ according to the plasmid extraction procedure used [22]; therefore, the procedure of Kado and Liu was selected in this study because it was rapid and permitted extraction of both small and large plasmids. The chromosomal DNA, which could mask plasmids migrating at this level, was reduced significantly by heat treatment at $65^{\circ} \mathrm{C}$ for $2 \mathrm{~h}$.

A total of 60 strains, belonging to five species of Nocardia, appeared to be plasmid-free. The fact that the majority of Nocardia strains did not contain plasmids suggests that there is no selective pressure for plasmid acquisition. The lack of sufficient transfer events from strain to strain, or too low a copy number, could also be responsible for not finding plasmids in these nocardial isolates.

Based on the few reports in the literature, the relative frequency of plasmid-containing strains in this study is similar to those described by Kasweck et al. [3] and Jonsson et al. [23]. Thus, Kasweck et al. reported finding plasmids in four of 12 laboratory isolates of $N$. asteroides, with plasmid sizes ranging from 13 to $36 \mathrm{~kb}$, and Jonsson et al. found plasmids varying in size from $c .8$ to $>100 \mathrm{~kb}$, in 11 of 24 clinical isolates of $N$. asteroides.

The significance of plasmids for their host bacteria probably depends on their stability. The present results confirm that plasmids do not seem to be lost readily during laboratory cultivation and maintenance [3]. For this reason, when plasmid(s) is(are) present, plasmid analysis could be a means of strain comparison in an epidemiological evaluation of outbreaks of nocardial infections [24] or in recurrence of infection in an individual case [23].

The significance of the fact that the incidence of plasmid-bearing strains seems higher among $N$. farcinica than in $N$. asteroides strains, particularly among strains isolated in the Paris area, requires further investigation. Thus, restriction endonuclease analysis of these plasmids and DNA-DNA hybridisation studies may indicate similarity among isolates, and suggest common sources of exposure.

From the data presented above, it can be concluded that there may be a correlation between the incidence of plasmid-harbouring strains and primary cutaneous localisation of infection. Surprisingly, plasmid bands were demonstrated in Nocardia spp. isolated from this site except $N$. brasiliensis, even though this species is known to be predominant in primary cutaneous nocardiosis [25]. Plasmid bands detected in $N$. otitidiscaviarum, a species also frequently involved in primary cutaneous infection [26], were of lower mol.wt than plasmid bands carried by $N$. asteroides and $N$. farcinica strains isolated from cutaneous sites. For this reason, it is important to investigate more isolates from cutaneous lesions. It would be of interest to determine whether there is a relationship between these plasmids and the ability of nocardiae to cause primary cutaneous disease.

The presence of plasmids in nocardiae could not be associated with specific phenotypic traits such as resistance to antibiotics or enzymic activity. Moreover, these plasmids appear not to be involved directly in virulence, because in man, strains lacking plasmids were shown to be as effective in causing nocardiosis as those with plasmid(s). However, continued investigation for such correlation is needed because the incidence of plasmid-bearing strains appears to be higher among $N$. farcinica isolates than among $N$. asteroides isolates. Other investigators have suggested that $N$. farcinica infection is characterised by higher rates of disseminated disease, antimicrobial resistance and mortality than other Nocardia spp. [27].

The information on the plasmid profiles of different strains of Nocardia reported here may offer greater 
insight into both plasmid and nocardial ecology. Additional prospective studies are necessary to trace the plasmid evolutionary behaviour within each species to understand the functional roles of these extra-chromosomal elements in nocardial biology.

\section{References}

1. Goodfellow M, Lechevalier MP. Nocardioforms, genus Nocardia Trevisan 1889, 9AL. In: Williams ST, Sharpe ME, Holt, JG (eds) Bergey's Manual of determinative bacteriology, vol 4. Baltimore, Williams and Wilkins. 1989: 2350-2361.

2. Beaman BL, Beaman L. Nocardia species: host-parasite relationships. Clin Microbiol Rev 1994; 7: 213-264.

3. Kasweck KL, Little ML, Bradley SG. Characteristics of plasmids in Nocardia asteroides. Actinomycetes and Related Organisms 1981; 16: 57-63.

4. Kasweck KL, Little ML, Bradley SG. Plasmid in mating strains of Nocardia asteroides. Dev Industr Microbiol 1982; 23: $279-286$

5. Boiron P, Provost F, Chevrier G, Dupont B. Review of nocardial infections in France 1987 to 1990. Eur J Clin Microbiol Infect Dis 1992; 11: 709-714.

6. Desmond EP, Flores M. Mouse pathogenicity studies of Nocardia asteroides complex species and clinical correlation with human isolates. FEMS Microbiol Lett 1993; 110: 281284

7. Wallace RJ, Tsukamura M, Brown BA et al. Cefotaximeresistant Nocardia asteroides strains are isolates of the controversial species Nocardia farcinica. J Clin Microbiol 1990; 28: 2726-2732.

8. Wallace RJ, Brown BA, Tsukamura M, Brown JM, Onyi GO Clinical and laboratory features of Nocardia nova. J Clin Microbiol 1991; 29: 2407-2411.

9. Jones KL. Fresh isolates of actinomycetes in which the presence of sporangeous aerial mycelia is a fluctuating characteristic. J Bacteriol 1949; 57: 141-145.

10. Staneck JL, Roberts GD. Simplified approach to identification of aerobic actinomycetes by thin-layer chromatography. Appl Microbiol 1974; 28: 226-231.

11. Minnikin DE, Alshamaony L, Goodfellow M. Differentiation of Mycobacterium, Nocardia, and related taxa by thin-layer chromatographic analysis of whole-organism methanolysates. $J$ Gen Microbiol 1975; 88: 200-204.

12. Kado CI, Liu S-T. Rapid procedure for detection and isolation of large and small plasmids. J Bacteriol 1981; 145: 13651373.
13. Chabbert YA, Roussel A, Wichitz JL, Sanson-Le Pors M-J Courvalin P. Restriction endonuclease generated patterns of plasmids belonging to incompatibility groups, Il, C, M and N; application to plasmid taxonomy and epidemiology. In: Timmis $\mathrm{KN}$, Pühler A (eds) Plasmids in medical, environmental and commercial importance. Amsterdam, Elsevier/North-Holland Biomedical Press. 1979: 183-192.

14. Sambrook J, Fritsch EF, Maniatis T (eds). Molecular cloning. A laboratory manual, 2nd edn. Cold Spring Harbor, Cold Spring Harbor Laboratory Press. 1989.

15. Boiron P, Provost F. Characterization of Nocardia, Rhodococcus and Gordona species by in vitro susceptibility testing. Int $J$ Med Microbiol 1990; 274: 203-213.

16. Acar J, Bergogne-Bérézin E, Chardon $\mathrm{H}$ et al. Antibiogram Committee of the French Society for Microbiology 1994 Statement. Path Biol 1994; 42: I-VIII.

17. Boiron P, Provost F. Enzymatic characterization of Nocardia spp. and related bacteria by API ZYM profile. Mycopathologia 1990; 110: $51-56$

18. Adams JN, Brownell GH. Genetic studies in Nocardia erythropolis. In: Goodfellow M, Brownell GH, Serrano JA (eds) The biology of the nocardiae. London, Academic Press. 1976: 285-309.

19. Kirby R, Usdin K. The isolation and restriction mapping of a miniplasmid from the Actinomycete Nocardia corallina. FEMS Microbiol Lett 1985; 27: 57-59.

20. Moretti P, Hintermann G, Hütter R. Isolation and characterization of an extrachromosomal element from Nocardia mediterranei. Plasmid 1985; 14: 126-133.

21. Oh YK, Fare LR, Taylor DP, Widger J, Nisbet LJ. A cryptic plasmid from Nocardia orientalis NRRL 2452, a vancomycin producer. J Antibiot Tokyo 1986; 39: 694-698.

22. Bertin A. Comparison of several procedures for plasmid profile determination in Escherichia coli. J Microbiol Methods 1995 22: $109-117$.

23. Jonsson S, Wallace RJ, Hull SI, Musher DM. Recurrent Nocardia pneumonia in an adult with chronic granulomatous disease. Am Rev Respir Dis 1986; 133: 932-934.

24. Stevens DA, Peir AC, Beaman ML, Morozumi PA, Lovett IS, Houang ET. Laboratory evaluation of an outbreak of nocardiosis in immunocompromised hosts. Am J Med 1981; 71: $928-934$.

25. Smego RA, Gallis HA. The clinical spectrum of Nocardia brasiliensis infection in the United States. Rev Infect Dis 1984; 6: $164-180$.

26. Clark NM, Braun DK, Pasternak A, Chenoweth CE. Primary cutaneous Nocardia otitidiscaviarum infection: case report and review. Clin Infect Dis 1995; 20: 1266-1270.

27. McNeil MM, Brown JM. The medically important aerobic actinomycetes: epidemiology and microbiology. Clin Microbiol Rev 1994; 7: 357-417. 